\title{
Design of a Miniaturized Dual-Band Frequency Reconfigurable Antenna
}

\author{
JiaMing Xia \\ College of \\ Communication \\ Engineering, Chengdu \\ University of Information \\ Technology \\ Chengdu, China
}

\author{
Hao Zou \\ College of \\ Communication \\ Engineering, Chengdu \\ University of Information \\ Technology \\ Chengdu, China
}

\author{
QiuQiang Luo \\ College of \\ Communication \\ Engineering, Chengdu \\ University of Information \\ Technology \\ Chengdu, China
}

\author{
Meng Li \\ College of \\ Communication \\ Engineering, Chengdu \\ University of Information \\ Technology \\ Chengdu, China
}

\begin{abstract}
A miniaturized dual-frequency reconfigurable antenna is proposed in this paper. The antenna frequency can be reconstructed by connecting two varactors with a $1 / 4$ wavelength branch. The antenna is designed on a FR 4 substrate with a relative permittivity 4.4. The overall size of the antenna is only $18.79 \mathrm{~mm} \times 15.98 \mathrm{~mm} \times 1 \mathrm{~mm}$. The three-dimensional simulation tool is used to obtain two adjustable frequency ranges of $5.34-5.45 \mathrm{GHz}$ and $7.65-7.95 \mathrm{GHz}$. The antenna is suitable for modern wireless communication applications.
\end{abstract}

Keywords: miniaturized antenna; dual band; reconfigurable antenna; L-shaped slot line

\section{INTRODUCTION}

In recent years, wireless communication systems have flourished. In modern wireless communication systems, the available RF spectrum is very crowded, and the problem of frequency reconfiguration needs to be solved. Modern wireless devices are expected to offer a number of features and support various services that operate at distinct frequencies. They have to meet strict size limitations as well offer attractive form factor and aesthetics. Since different wireless services utilize technologies operating at different frequencies, multiple antennas need to be incorporated making the fulfilment of size limitations a challenging task. A single reconfigurable antenna supporting operation at two different frequencies using varactors is one of the available options.

Currently, reconfigurable antennas are divided into frequency reconfigurable antennas [1-2], pattern reconfigurable antennas [3-4], and polarization reconfigurable antennas [5-6]. There are many methods to achieve frequency reconfigurability. The dual-frequency reconfigurable of the antenna is achieved by using a single RF MEMS switch [7]. However, this structure cannot continuously adjust the frequency. A dual-frequency operation is implemented by loading a U-shaped slot line, and frequency reconfigurable feature is realized by using two PIN diodes [8]. Five PIN diodes are placed in the slot in [9]. The microstrip slot antenna inside realizes frequency conversion in six frequency bands from $2.2 \mathrm{GHz}$ to $4.75 \mathrm{GHz}$. A miniaturized frequency reconfigurable monopole antenna combining ultra-wideband and narrow-band is proposed in [10], and has five states for switching. The antenna structure has a relatively small size of $40 \mathrm{~mm} \times 40 \mathrm{~mm}$. The literature [11] designed a frequency reconfigurable antenna based on a half-mode substrate integrated waveguide (HMSIW). The resonant frequency of the antenna is adjustable from 2.99 $\mathrm{GHz}$ to $3.59 \mathrm{GHz}$ in the range of $0-30 \mathrm{~V}$ bias voltage. An antenna structure in which both frequency and pattern can be reconstructed is proposed in [12]. The antenna obtains three reconfigurable frequency bands by placing two switches in the slot, which are $1.82 \mathrm{GHz}, 1.92 \mathrm{GHz}$ and $2.10 \mathrm{GHz}$.

In this paper, a dual-frequency miniaturized reconfigurable antenna is presented. Two varactors are connected to the $1 / 4$ wavelength branch on the ground plane side, the two frequency bands can be continuously tuned by varying the $\mathrm{dc}$ bias voltage.

\section{PROPOSED ANTENNA DESIGN}

The antenna model proposed in this paper is shown in Figure 1. The initial model of the antenna is a microstrip patch antenna. The radiation patch size is $l_{0} \times w_{0}$, and the total antenna size is $L \times W \times h$. The antenna is designed on a FR4 board with a relative permittivity of 4.4 , tangential loss of 0.002 and a thickness of $1 \mathrm{~mm}$.

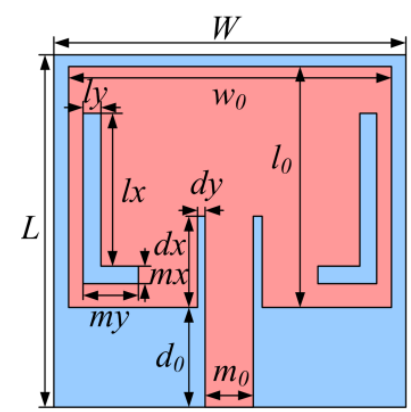

(a)

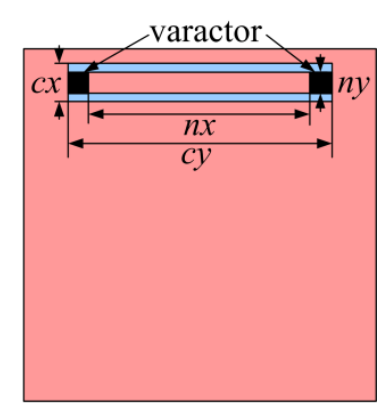

(b)
Fig. 1. Geometry of the proposed antenna: (a) front view, (b) back view of the proposed antenna.

$$
\begin{gathered}
w_{0}=\frac{c}{2 f}\left(\frac{\varepsilon_{r}+1}{2}\right)^{-\frac{1}{2}} \\
\varepsilon_{e}=\frac{\varepsilon_{r}+1}{2}+\frac{\varepsilon_{r}-1}{2}\left(1+12 \frac{h}{w_{0}}\right)^{-\frac{1}{2}} \\
l_{0}=\frac{c}{2 f \sqrt{\varepsilon_{e}}}
\end{gathered}
$$


Where $c$ is the speed of light in the vacuum and $\varepsilon_{r}$ is the relative dielectric constant of the dielectric substrate. $\varepsilon_{e}$ is the effective dielectric constant of the dielectric substrate. Two Lshaped slot lines in the antenna structure are symmetrically etched on the radiation patch, and the grounding is slotted to change the surface current path on the radiation patch and achieve dual operating frequency. A branch is added to the rectangular opening slot and two varactors are implemented to get the current loop. The varactor capacitance is adjusted by varying the dc bias voltage. The physical dimensions of the antenna are shown in Table 1.

Table 1 Dimensions of the proposed antenna

\begin{tabular}{|c|c|c|c|}
\hline Parameters & Value $(\mathrm{mm})$ & Parameters & Value $(\mathrm{mm})$ \\
\hline$L$ & 18.79 & $d y$ & 0.20 \\
\hline$W$ & 15.98 & $d x$ & 4.40 \\
\hline$l_{0}$ & 11.60 & $d_{0}$ & 6.80 \\
\hline$w_{0}$ & 15.20 & $m_{0}$ & 1.90 \\
\hline$l y$ & 1.00 & $c y$ & 11.50 \\
\hline$l x$ & 8.00 & $c x$ & 1.50 \\
\hline$m y$ & 3.00 & $n y$ & 9.50 \\
\hline$m x$ & 1.00 & $n x$ & 0.90 \\
\hline
\end{tabular}

\section{SIMULATION RESULTS}

The designed antenna model was constructed using HFSS15.0 $3 \mathrm{D}$ simulation tool. Figure 2 shows the $S_{11}$ of the antenna without varactors. As can be seen from the figure, the antenna can operate at two frequencies of $5.63 \mathrm{GHz}$ and $8.02 \mathrm{GHz}$, and the return loss $\mathrm{S}_{11}<-10 \mathrm{~dB}$, which satisfies the engineering application requirements of antenna.

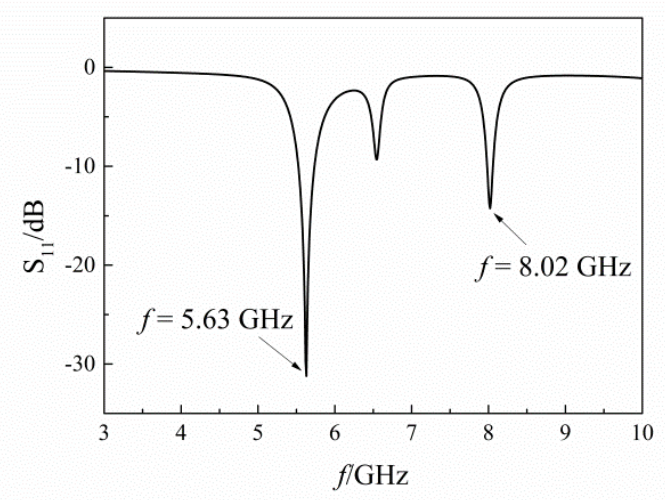

Fig. 2. Simulated reflection coefficient of the proposed antenna.

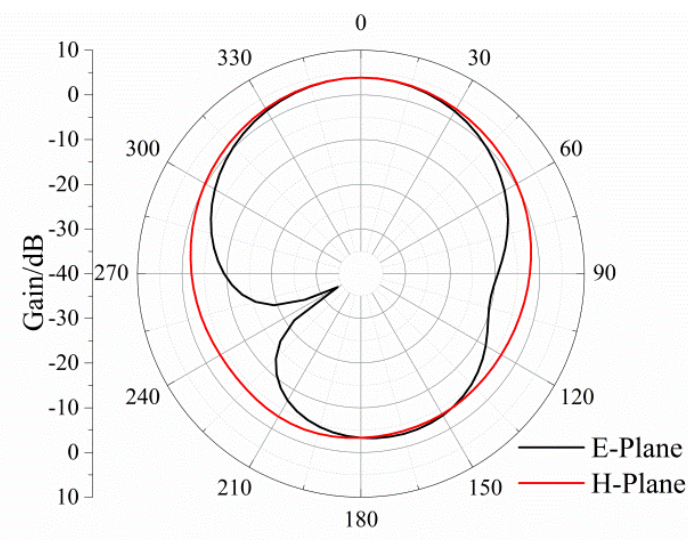

Fig. 3. Radiation pattern of the proposed antenna at $5.63 \mathrm{GHz}$.

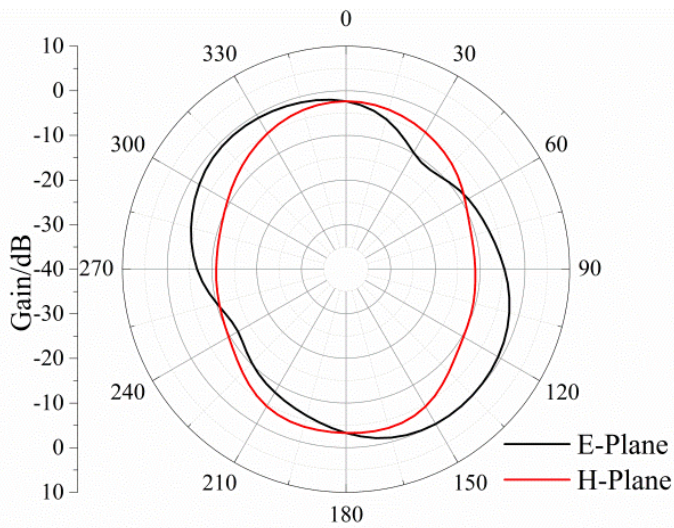

Fig. 4. Radiation pattern of the proposed antenna at $8.02 \mathrm{GHz}$.

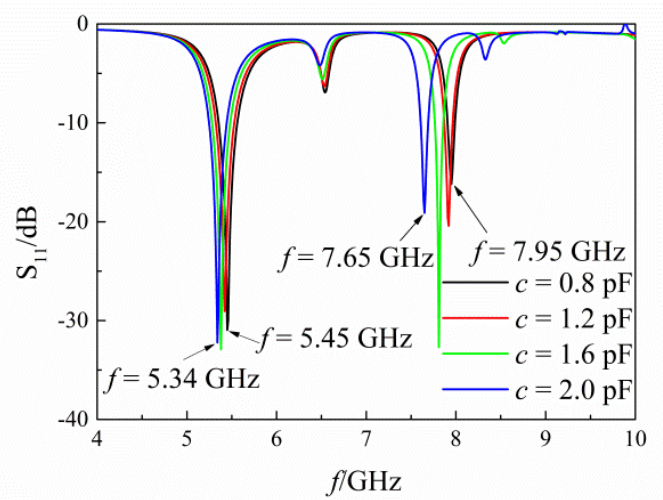

Fig. 5. Simulated reflection coefficient for different varactor capacitance.

Figure 3 and figure 4 are the view of the E-plane and H-plane patterns of the antenna at $5.63 \mathrm{GHz}$ and $8.02 \mathrm{GHz}$, respectively. Figure 5 shows the simulation return loss of the antenna with varactors. It can be clearly seen from the figure that when varactor capacitance $c$ from $0.8 \mathrm{pF}$ to $2.0 \mathrm{pF}$, the two operating frequencies of the antenna are tuned from 5.34 $\mathrm{GHz}$ to $5.45 \mathrm{GHz}$ and from $7.65 \mathrm{GHz}$ to $7.95 \mathrm{GHz}$. So, The frequency reconfigurable antenna is achieved. The frequency can be continuously adjusted by selecting suitable varactor. 


\section{CONCLUSION}

This paper proposes a miniaturized dual band frequency reconfigurable patch antenna that can operate at $5.63 \mathrm{GHz}$ and $8.02 \mathrm{GHz}$ without loading varactor. The reconfigurable frequency of the antenna can be achieved by loading two symmetrically distributed varactors on the ground plane. The frequency adjustment ranges are from $5.34 \mathrm{GHz}$ to $5.45 \mathrm{GHz}$ and from $7.65 \mathrm{GHz}$ to $7.95 \mathrm{GHz}$. The antenna is suitable for modern wireless communication systems with small size and compact structure

\section{REFERENCES}

[1] X. W. Zhao, S. Riaz, "A Dual-Band Frequency Reconfigurable MIMO atch-Slot Antenna Based on Reconfigurable Microstrip Feedline," IEEE Access, vol. 6, pp. 41450-41457, 2018.

[2] Yuan-Ming, Cai , et al. "A Low-Profile Frequency Reconfigurable Grid-Slotted Patch Antenna," IEEE Access, vol. 6, pp. 36305-36312, 2018.

[3] J. Row and Y. Wu, "Pattern Reconfigurable Slotted-Patch Array," IEEE Transactions on Antennas and Propagation, vol. 66, no. 3, pp. 1580-1583, March 2018.

[4] G. P. Jin, M. Li, D. Liu, G. J. Zeng, "A Simple Planar Pattern-Reconfigurable Antenna Based on Arc Dipoles," IEEE Antennas and Wireless Propagation Letters, vol. 17, no. 9, pp. 1664-1668, Sept. 2018.

[5] A. Panahi, X. L. Bao, K. Yang, O. O'Conchubhair, M. J. Ammann, "A Simple Polarization Reconfigurable Printed Monopole Antenna," IEEE Transactions on Antennas and Propagation, vol. 63, no. 11, pp. 5129-5134, Nov. 2015.

[6] P. Y. Qin, A. R. Weily, Y. J. Guo, C. Liang, "Polarization Reconfigurable U-Slot Patch Antenna," IEEE Transactions on Antennas and Propagation, vol. 58, no. 10, pp. 3383-3388, Oct. 2010.

[7] A. Zohur, H. Mopidevi, D. Rodrigo, M. Unlu, L. Jofre, B. A. Cetiner, "RF MEMS Reconfigurable Two-Band Antenna," IEEE Antennas and Wireless Propagation Letters, vol. 12, pp. 72-75, 2013.

[8] L. Han, C. Wang, X. Chen, W. Zhang, "Compact Frequency-Reconfigurable Slot Antenna for Wireless Applications," IEEE Antennas and Wireless Propagation Letters, vol. 15, pp. 1795-1798, 2016.

[9] H. A. Majid, M. K. A. Rahim, M. R. Hamid, M. F. Ismail, "A Compact Frequency-Reconfigurable Narrowband Microstrip Slot Antenna," IEEE Antennas and Wireless Propagation Letters, vol. 11, pp. 616-619, 2012.

[10] H. Boudaghi, M. Azarmanesh, M. Mehranpour, "A Frequency-Reconfigurable Monopole Antenna Using Switchable Slotted Ground Structure," IEEE Antennas and Wireless Propagation Letters, vol. 11, pp. 655-658, 2012.

[11] S. Sam and S. Lim, "Compact Frequency-Reconfigurable Half-Mode Substrate-Integrated Waveguide Antenna," IEEE Antennas and Wireless Propagation Letters, vol. 12, pp. 951-954, 2013.
[12] H. A. Majid, M. K. A. Rahim, M. R. Hamid and M. F. Ismail, "Frequency and Pattern Reconfigurable Slot Antenna," IEEE Transactions on Antennas and Propagation, vol. 62, no. 10, pp. 5339-5343, Oct. 2014 